\title{
Doctors under Threat and Physical Assault
}

\author{
Dinesh Rokaya ${ }^{1}$ Manoj Humagain² \\ ${ }^{1}$ International College of Dentistry, Walailuk University, \\ Nakhon Si Thammarat, Thailand \\ 2Department of Periodontics, Kathmandu University School of \\ Medical Sciences, Kavre, Nepal
}

Eur Dent Res Biomater J 2020;1:32

Recently, the incidence of group attacks and physical assaults on doctors, vandalizing hospitals, and on-the-spot demand for the compensation after death of a patient from any cause is increasing in the Indian subcontinent region, including Nepal..$^{1-5}$ It is found that certain group of people, called "dalal" in local language, are responsible for the assault. They reach the incident spot and pretend as patient parties and demand to be compensated as they get a certain percentage from the compensation. The doctors and hospital personnel are threatened by the crowd and compelled to pay a huge amount as compensation without having the investigation and decision from the concerned authority.

World Health Organization (WHO) points that medical negligence is among the top-10 killers in the world and unintended medical errors have become a big threat to patient safety. One in 10 hospital admissions leads to an adverse event and 1 in 300 admissions to death. ${ }^{6}$ Negative experiences after the treatment among doctors are not uncommon even in developed countries like Norway and the United States. ${ }^{7}$ The young doctors, specialists, and residents in Nepal feel insecure while working and are disappointed.

Previously, the doctors in Nepal were under strike for a week following the one-sided decision made by the cabinet ministers on September 18, 2017, that the doctor would be required to compensate the victims of any negligence during treatment in hospital. ${ }^{8}$ Since then, the Nepal Medical Association (NMA) had requested all doctors in Nepal to shut down all medical schools, hospitals, clinics, and nursing homes, and provide emergency services only. ${ }^{9}$ The NMA had demanded that the decision made by the cabinet be taken back, the law "Jail without Bail" be implemented, and the medical fraternity be respected. The agitating doctors sought a strict law that does not allow the court to release those who attack them and vandalize hospitals ("Jail without Bail"). ${ }^{1}$ The government often fails to implement the commitments, leading to strikes.

There is an immediate need for the government to reform the law providing the security to the doctors which is the

\author{
Address for correspondence Dinesh Rokaya, BDS, MSc, PhD, \\ International College of Dentistry, Walailuk University, \\ Nakhon Si Thammarat 80160, Thailand \\ (e-mail: dineshrokaya115@hotmail.com).
}

government's responsibility toward the citizens. There should be a provision of investigation by the concerned authority and necessary actions should be taken by law for the negligence and/or malpractice. In addition, the government should fulfill another requirement like providing a favorable working environment with proper medical facilities, raising the salary of doctors, and providing adequate opportunities for academic and professional development. ${ }^{10}$

\section{Conflict of Interest}

None declared.

\section{References}

1 Doctor's on strike. Available at: http://www.nepalitimes. com/blogs/thebrief/2017/09/22/doctors-on-strike/. Updated September 2017. Accessed March 2, 2020

2 Ambesh P. Violence against doctors in the Indian subcontinent: a rising bane. Indian Heart J 2016;68(5):749-750

3 Sharma GK, Osti B, Sharma B. Physicians persecuted for ethical practice in Nepal. Lancet 2002;359(9316):1519

4 Huang SL, Ding XY. Violence against Chinese health-care workers. Lancet $2011 ; 377(9779): 1747$

5 Yu D, Li T. Doctor stabbed to death two days after warning in The Lancet. Lancet 2011;377(9766):639

6 Medical errors in top 10 killers: WHO. Available at: http:// timesofindia.indiatimes.com/india/Medical-errors-in-top-10killers-WHO/articleshow/8032059.cms?referral=PM. Updated April 2011. Accessed March 2, 2020

7 Kristiansen IS, Førde OH, Aasland O, Hotvedt R, Johnsen R, Førde R. Threats from patients and their effects on medical decision making: a cross-sectional, randomised trial. Lancet 2001;357(9264):1258-1261

8 Government to make doctors liable for 'botched' treatment. Available at: http://english.onlinekhabar.com/2017/ 09/18/406864.html. Updated September 2017. Accessed March 2, 2020

9 Doctors shut all hospital departments except emergency across Nepal. Available at: http://english.onlinekhabar. com/2017/09/22/407079.html. Updated Sep 2017. Accessed March 2, 2020

10 Pandey NR. Emergency medicine in Nepal: present practice and direction for future. Int J Emerg Med 2016;9(1):20
DOI https://doi.org/

10.1055/s-0040-1710137.
(C)2020 Dental Investigation Society
License terms

() (1) $\Theta \circledast$ 